\title{
Structural and functional analysis of SET8, a histone H4 Lys-20 methyltransferase
}

\author{
Jean-François Couture, ${ }^{1}$ Evys Collazo, ${ }^{1}$ Joseph S. Brunzelle, ${ }^{2}$ and Raymond C. Trievel ${ }^{1,3}$ \\ ${ }^{1}$ Department of Biological Chemistry, University of Michigan, Ann Arbor, Michigan 48109, USA; ${ }^{2}$ Life Sciences \\ Collaborative Access Team, Advanced Photon Source, Argonne National Laboratory, Argonne, Illinois 60439, USA
}

SET8 (also known as PR-SET7) is a histone H4-Lys-20-specific methyltransferase that is implicated in cell-cycle-dependent transcriptional silencing and mitotic regulation in metazoans. Herein we report the crystal structure of human SET8 (hSET8) bound to a histone H4 peptide bearing Lys-20 and the product cofactor S-adenosylhomocysteine. Histone $\mathrm{H} 4$ intercalates in the substrate-binding cleft as an extended parallel $\beta$-strand. Residues preceding Lys-20 in $\mathrm{H} 4$ engage in an extensive array of salt bridge, hydrogen bond, and van der Waals interactions with hSET8, while the C-terminal residues bind through predominantly hydrophobic interactions. Mutational analysis of both the substrate-binding cleft and histone $\mathrm{H} 4$ reveals that interactions with residues in the $\mathrm{N}$ and $\mathrm{C}$ termini of the $\mathrm{H} 4$ peptide are critical for conferring substrate specificity. Finally, analysis of the product specificity indicates that hSET8 is a monomethylase, consistent with its role in the maintenance of Lys-20 monomethylation during cell division.

[Keywords: Histone modifications; protein lysine methylation; SET domain; transcription; mitosis; substrate specificity]

Received March 25, 2005; revised version accepted May 2, 2005.

Nucleosomes are the fundamental unit of packaging of DNA in eukaryotes and are composed of 146 bp of DNA wound around a histone octamer comprised of two copies each of the core histones $\mathrm{H} 2 \mathrm{~A}, \mathrm{H} 2 \mathrm{~B}, \mathrm{H} 3$, and H4. In the presence of linker histones, such as $\mathrm{H} 1$, nucleosomes can be arranged into higher-ordered structures, further compacting the DNA and creating a repressive environment that silences transcription. Both core and linker histones undergo a myriad of post-translational modifications that govern numerous genomic functions, including transcription, mitosis, DNA repair, and recombination (Fischle et al. 2003). Site-specific methylation of lysines, which occurs within histones $\mathrm{H} 1, \mathrm{H} 3$, and $\mathrm{H} 4$, has recently emerged as an important modification in the epigenetic control of gene expression (Sims et al. 2003; Kuzmichev et al. 2004). Methylation of Lys-20 in histone $\mathrm{H} 4$ is unique among these sites because of its involvement in a diverse array of nuclear processes. Lys20 methylation is enriched in transcriptionally silent regions (Fang et al. 2002; Nishioka et al. 2002), and trimethylation of this lysine selectively marks pericentric heterochromatin (Schotta et al. 2004). In addition, this modification has been linked to mitotic regulation in

${ }^{3}$ Corresponding author.

E-MAIL rtrievel@umich.edu; FAX (734) 763-4581.

Article published online ahead of print. Article and publication date are at http://www.genesdev.org/cgi/doi/10.1101/gad.1318405. metazoans (Julien and Herr 2004; Karachentsev et al. 2005), cellular aging in mammals (Sarg et al. 2002), and DNA damage checkpoint control in the cell cycle of Schizosaccharomyces pombe (Sanders et al. 2004).

Research by various groups has resulted in the identification of several histone H4 Lys-20-specific protein methyltransferases (PKMTs), including metazoan SET8 (also known as PR-SET7) (Fang et al. 2002; Nishioka et al. 2002), Drosophila ASH1 (Beisel et al. 2002), murine NSD1 (Rayasam et al. 2003), and mammalian SUV4$20 \mathrm{H} 1 / 2$ (Schotta et al. 2004) and its Schizosaccharomyces pombe ortholog SET9 (Sanders et al. 2004). These enzymes are members of the SET domain methyltransferase family that catalyze the methylation of select lysines in proteins using the cofactor S-adenosylmethionine (AdoMet) (Trievel 2004). SET8 is the most studied of the Lys-20-specific PKMTs and has been shown to function in transcriptional silencing in metazoans (Rice et al. 2002). Expression of this PKMT fluctuates during the cell cycle and peaks during the G2/M transition. During M phase, SET8 becomes phosphorylated /Georgi et al. 2002) and is recruited to mitotic chromosomes (Rice et al. 2002). Both the expression and localization of SET8 coincide with global fluctuations in the level of Lys-20 methylation during the cell cycle, which peaks during mitosis. The resulting Lys-20 methylation pattern can be maintained beyond a single round of cell division, suggesting that SET8 propagates an epigenetic 
imprint in transcriptional silencing (Rice et al. 2002; Karachentsev et al. 2005).

In addition to cell-cycle-dependent gene silencing, this PKMT also plays a pivotal role in mitotic regulation in metazoans. In Drosophila, loss-of-function mutations in the SET8 gene result in lethality during the larval to pupal transition in development (Nishioka et al. 2002; Karachentsev et al. 2005). An analysis of the SET8 mutants reveals a significant decrease in histone H4 Lys-20 mono-, di-, and trimethylation in comparison to the chromatin of wild-type larvae and correlates with a general loss in heterochromatic silencing (Karachentsev et al. 2005). Larvae with SET8-null mutations also exhibit abnormalities in mitosis that result in reduced cell size and multinucleation, implying that the cells have undergone endoreplicative cell division. Similar phenomena have been observed when SET8 expression is perturbed in HeLa cell lines (Julien and Herr 2004). RNA interference of the gene encoding HCF-1 (herpes simplex virus host cell factor-1), a transcription factor that regulates the expression of SET8, disrupts proper expression of the enzyme, resulting in altered levels of monomethyl-Lys20 during mitosis. These aberrations coincide with severe mitotic defects including improper chromosome segregation during metaphase, aberrant cytokinesis, and multinucleated daughter cells, correlating with the effects of the SET8-null mutants in Drosophila. Taken together, these studies firmly establish that SET8 has a critical role in mitotic regulation in metazoans through maintenance of Lys-20 monomethylation during cell division.

To gain greater insights into the biological functions of this enzyme, we have determined the crystal structure of human SET8 (hSET8) bound to a histone H4 peptide bearing Lys-20 and the product cofactor S-adenosylhomocysteine (AdoHcy). The structure of the ternary complex and the accompanying biochemical analysis reveal the mechanism by which hSET8 specifically recognizes Lys-20 in H4. In addition, the structure elucidates a novel interaction between the cofactor and histone $\mathrm{H} 4$ that is not observed in other SET-domain PKMTs. Finally, product specificity analysis indicates that hSET8 is a bona fide histone H4 Lys-20 monomethylase, correlating with its functions in transcriptional silencing and maintaining Lys-20 monomethylation during mitosis.

\section{Results and Discussion}

\section{Overall structure of the hSET8 ternary complex}

To elucidate the structure of hSET8 in complex with histone $\mathrm{H} 4$, we cocrystallized a construct of the enzyme encoding the catalytic SET domain (residues 191-352) with a 10 -residue $\mathrm{H} 4$ peptide (A-K-R-H-R-K $\mathbf{2 0}_{\mathbf{2}}$-V-L-R-D) and the product AdoHcy. Removal of the N-terminal 190 residues was necessary in order to obtain diffractionquality crystals of the complex, but did not impair the activity of the enzyme (see below). The structure was determined at $2.0 \AA$ resolution by selenomethionyl multiple wavelength anomalous dispersion (MAD) phasing using an I220M mutant to enhance the Se anomalous signal (Fig. 1A). The experimentally phased structure was then used as a molecular replacement model to determine the structure of the wild-type hSET8 in complex with the histone $\mathrm{H} 4$ peptide and AdoHcy at $1.45 \AA$ resolution (Table 1).

The overall fold of the catalytic domain of hSET8 is structurally conserved with other SET-domain PKMTs (Trievel 2004). The SET domain is composed of a singleturn $3_{10}$ helix $\left(3_{10-1}\right)$ and $12 \beta$-strands $(\beta 1-\beta 12)$ arranged into four antiparallel $\beta$-sheets and a single parallel $\beta$-sheet (Fig. 1B; Trievel et al. 2002). An $\alpha$-helix $(\alpha 2)$ is inserted between the $\beta 5$ - and $\beta 6$-strands of the SET domain, as is observed in the structures of the histone $\mathrm{H} 3$ methyltransferases Neurospora DIM-5 (Zhang et al. 2002) and human SET7/9 (Wilson et al. 2002). This helix
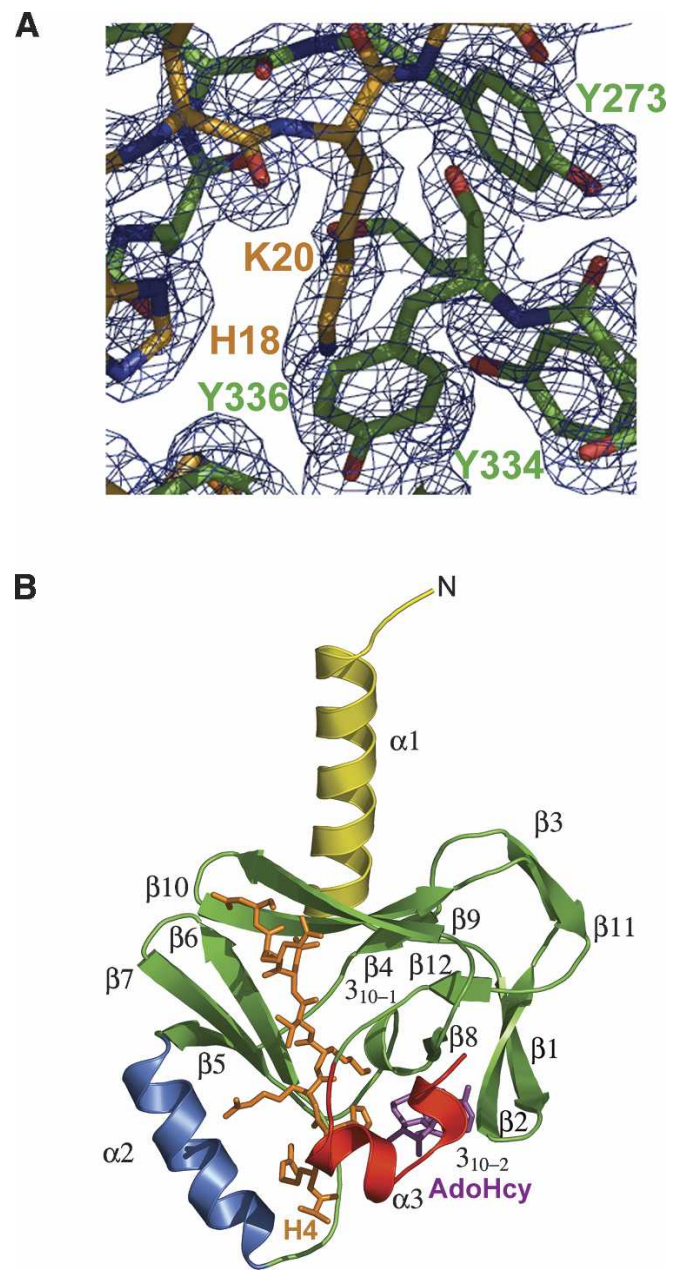

Figure 1. Crystal structure of hSET8. (A) Experimental SeMAD phased electron density map at 2.0 A resolution illustrating the active site of hSET 8 bound to Lys-20 in histone H4. The map is contoured at $1.0 \mathrm{\sigma}$. The carbon atoms of hSET 8 and the histone $\mathrm{H} 4$ residues are displayed and labeled in green and gold, respectively. (B) Ribbon diagram of the secondary structure of hSET 8 with the $\beta$-strands and $\alpha$ - and $3_{10}$-helices denoted. The SET, nSET, iSET, and cSET regions are depicted in green, yellow, blue, and red, respectively, while AdoHcy and the H4 peptide are represented in magenta and orange, respectively. 
Table 1. Data and refinement statistics for the crystal structure of hSET8 bound to AdoHcy and a histone H4 peptide

\begin{tabular}{|c|c|c|c|c|}
\hline \multirow[b]{2}{*}{ Data collection } & \multirow[b]{2}{*}{ Native } & \multicolumn{3}{|c|}{ Se-Met data of I220M mutant } \\
\hline & & Inflection & High remote & Peak \\
\hline Space group: P1 & $\begin{array}{l}a=43.9, b=45.7, c=94.4 \\
\alpha=89.2, \beta=87.1, \gamma=90.7\end{array}$ & \multicolumn{3}{|c|}{$\begin{array}{c}\mathrm{a}=44.3, \mathrm{~b}=44.7, \mathrm{c}=52.3 \\
\alpha=64.8, \beta=88.8, \gamma=89.5\end{array}$} \\
\hline Wavelength $(\AA)$ & 0.9686 & 0.9792 & 0.9686 & 0.9791 \\
\hline Resolution $(\AA)$ & 1.45 & 2.0 & 2.0 & 2.0 \\
\hline $\mathrm{R}_{\text {merge }}(\%)$ & $4.2(19.2)^{\mathrm{a}}$ & $4.7(7.2)$ & $5.1(5.9)$ & $6.4(8.7)$ \\
\hline $\mathrm{I} / \sigma \mathrm{I}$ & $19.48(6.9)$ & $22.5(19.7)$ & $21.5(20.0)$ & $12.5(9.8)$ \\
\hline \multicolumn{5}{|l|}{ Reflections } \\
\hline Total & 405,744 & 96,027 & 95,740 & 68,780 \\
\hline Unique & 122,436 & 23,246 & 24,153 & 24,087 \\
\hline Completeness & $94.1(90.1)$ & $95.1(87.2)$ & $95.5(91.5)$ & $95.2(94.9)$ \\
\hline Phasing power & & 3.615 & 3.589 & 2.879 \\
\hline Sites found/Total & & & & $6 / 8$ \\
\hline F.O.M. ${ }^{b}$ & & & & 0.8328 \\
\hline \multicolumn{2}{|l|}{ Refinement (native) } & \multicolumn{3}{|l|}{ R.M.S. } \\
\hline Resolution Range & $10-1.45 \AA$ & & 0.008 \\
\hline 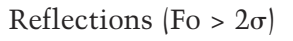 & 405,744 & \multicolumn{2}{|c|}{ Bond angles $\left({ }^{\circ}\right)$} & 1.188 \\
\hline Final Model & & \multicolumn{2}{|c|}{ B-factors $\left(\AA^{2}\right)$} & 16.15 \\
\hline Protein atoms & 5132 & & & \\
\hline H4/AdoHcy & $304 / 114$ & \multicolumn{3}{|c|}{ Average B-factors $\left(\AA^{2}\right)$} \\
\hline Water atoms & 1007 & \multicolumn{2}{|l|}{ Protein } & 14.37 \\
\hline R-factors ${ }^{\mathrm{c}}$ & & \multicolumn{2}{|c|}{ Histone H4/AdoHcy } & $15.27 / 8.16$ \\
\hline $\mathrm{R}_{\text {working }}$ & 16.9 & \multirow{2}{*}{\multicolumn{2}{|c|}{ Water }} & 26.22 \\
\hline $\mathrm{R}_{\text {free }}$ & 19.9 & & & \\
\hline
\end{tabular}

forms the inserted SET or iSET region, and variations in the sequence and structure of this motif play a key role in determining the substrate specificity of different PKMTs (Xiao et al. 2003b). In contrast, the $\mathrm{N}$ - and Cterminal regions that flank the SET domain of hSET8 (referred to as the nSET and cSET regions, respectively) are not conserved in the structures of other histone methyltransferases. In the nSET region, a single $\alpha$-helix $(\alpha 1)$ precedes the SET domain, similar to the N-terminal $\alpha$-helix of Rubisco large subunit methyltransferase (LSMT), a plant SET-domain enzyme (Trievel et al. 2002). The cSET region of hSET8 is composed of a short $\alpha$-helix $(\alpha 3)$ and a $3_{10}$ helix $\left(3_{10-2}\right)$ that pack against the cofactor and protein substrate-binding sites. Mutations within this region abrogate substrate binding and catalysis (see below), agreeing with the truncation studies reported by Zhang and colleagues (Fang et al. 2002).

\section{AdoMet-binding site}

The product AdoHcy adopts a horseshoe-shaped conformation in the cofactor-binding pocket that is formed by the $\beta 1-\beta 2$ turn, the loop preceding $\beta 6$, the $\beta 8$-strand, and the $\alpha 3$-helix in the cSET region (Fig. 1B). The adenine moiety of AdoHcy is sandwiched between the indole ring of Trp-349 and the aliphatic side chain of Lys-226, and the purine N6 and N7 atoms hydrogen-bond to the backbone carbonyl and amide groups of His-299, respectively (Fig. 2A). At the opposite end of the cofactor, the positively charged $\alpha$-amino group is recognized by a trigonal array of hydrogen bonds with the main chain carbonyl oxygens of Lys-226 and Arg-228 and the amide Os of Asn-298. In addition, the carboxylate moiety of the AdoHcy forms a highly conserved salt-bridge interaction with the guanidinium group of Arg-228 and also hydrogen-bonds to the hydroxyl of Tyr-271. Overall, the cofactor-binding mode is structurally conserved with other SET-domain methyltransferases and serves to orient the methyl group of AdoMet into the methyltransfer pore during catalysis (Trievel 2004).

Despite these similarities, a striking difference is observed in the interactions with the ribose moiety of AdoHcy in the hSET8 ternary complex. In the structures of other SET-domain PKMTs, the ribose hydroxyls of the cofactor are either solvent-exposed, such as in hSET7/9 (Xiao et al. 2003a) and Rubisco LSMT (Trievel et al. 2002), or hydrogen-bonded with neighboring residues, as is observed in DIM-5 (Zhang et al. 2003). However in the hSET8 ternary complex, the 3 '-OH hydroxyl engages in a direct hydrogen bond with the imidazole moiety of His18 in the histone H4 peptide (Fig. 2A). This novel substrate-cofactor interaction does not occur within other 
Couture et al.

A
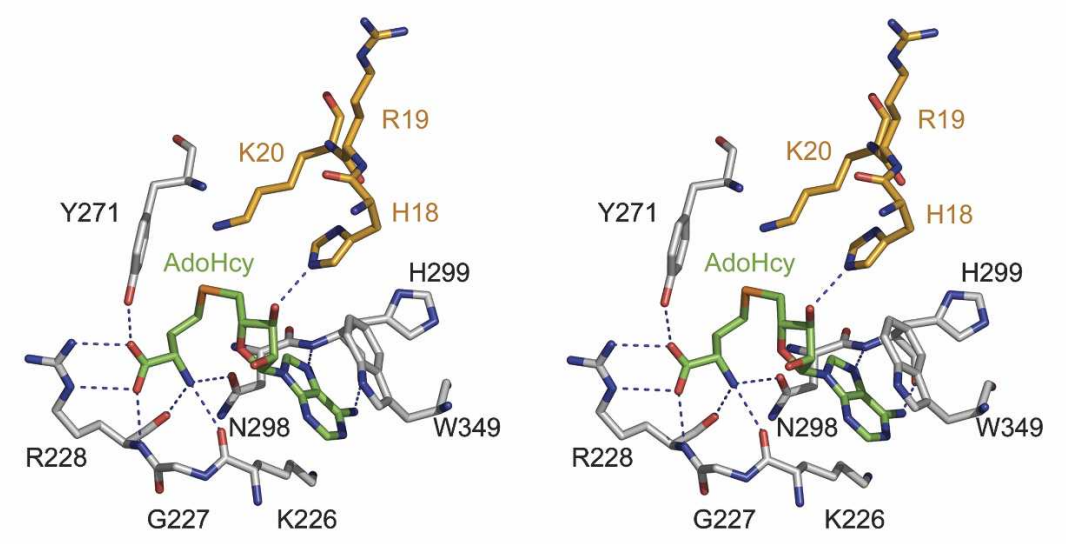

B

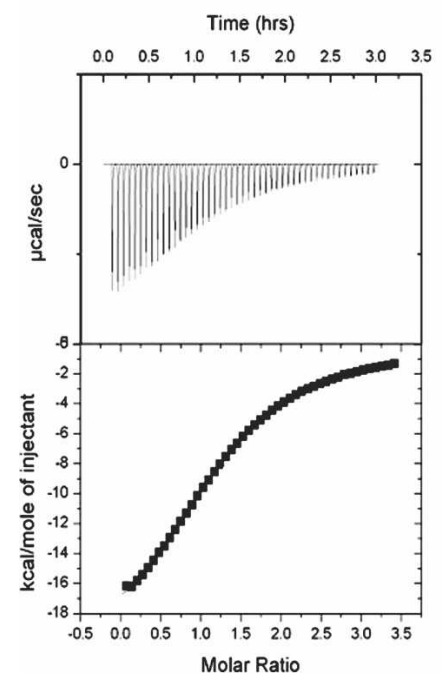

C

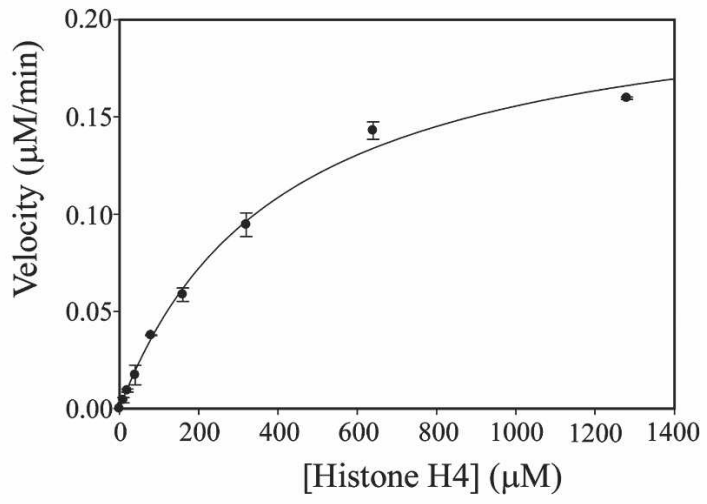

Figure 2. Cofactor-binding pocket. (A) Stereoview of the cofactor-binding cavity in complex with AdoHcy. The carbon atoms in hSET8, the cofactor, and the H4 peptide are depicted in gray, green, and gold, respectively. Hydrogen bonds are illustrated as dashed blue lines. $(B)$ ITC titration experiment with the wild-type histone H4 peptide and hSET8 (upper trace) and the fitted binding curve (lower trace). (C) Michaelis-Menten plot of the initial velocity versus substrate concentration for the methylation of the $\mathrm{H} 4$ peptide by hSET8.

SET-domain enzymes because the residues that line the floor of the protein substrate-binding cleft occlude the AdoMet-binding pocket, preventing direct contact between the histone and the cofactor. Using isothermal titration calorimetry (ITC) (Fig. 2B), we determined that mutation of His-18 to phenylalanine modestly affects the affinity of hSET8 for histone $\mathrm{H} 4$, whereas substitution of this residue by alanine (H18A) completely abolishes binding (Table 2). Interestingly, both the H18F and H18A substitutions severely abrogate AdoHcy binding (J.-F. Couture and R.C. Trievel, unpubl.), suggesting that the hydrogen bond between His-18 and the cofactor is important for high-affinity binding of AdoMet. However, steady-state kinetic analysis of native hSET8 (Fig. 2C) and the His-18 mutants reveals that the H18F mutant exhibits only a slight reduction in its substrate specificity $\left(k_{c a t} / K_{M}\right.$ value $)$ in comparison to the native H4 peptide, while the H18A mutant completely eliminates histone $\mathrm{H} 4$ methylation by hSET8. Collectively, these results suggest that the hydrogen bond between the cofactor and His-18 in histone $\mathrm{H} 4$ enhances the affinity of AdoMet for hSET8, but is not essential for catalysis.

\section{Histone $H 4$ recognition by hSET8}

The experimental map obtained from the Se-MAD phasing of hSET8 yielded unambiguous electron density for residues 16-24 in histone $\mathrm{H} 4$. The $\mathrm{H} 4$ peptide binds in a 
Table 2. Mutational analysis of histone $\mathrm{H} 4$ and the substrate binding cleft of hSET8

\begin{tabular}{|c|c|c|c|c|}
\hline hSET8 & $\mathrm{K}_{\mathrm{D}}(\mu \mathrm{M})$ & $K_{M}(\mu \mathrm{M})$ & $\begin{array}{c}k_{c a t} \\
\left(\min ^{-1}\right)\end{array}$ & $\begin{array}{c}k_{c a t} / K_{M} \\
\left(\mu M^{-1} \times \min ^{-1}\right) \\
\times 10^{3}\end{array}$ \\
\hline Wild type & $33 \pm 1$ & $400 \pm 30$ & $0.43 \pm 0.02$ & $1.1 \pm 0.1$ \\
\hline E259A & $>500$ & - & - & $0.06 \pm 0.01$ \\
\hline E259Q & $84 \pm 2$ & $870 \pm 7$ & $0.12 \pm 0.01$ & $0.14 \pm 0.01$ \\
\hline C270A & $>500$ & - & - & $0.09 \pm 0.02$ \\
\hline D338A & $>500$ & N.A. & N.A. & N.A. \\
\hline D338N & $>500$ & N.A. & N.A. & N.A. \\
\hline H347A & $>500$ & $1020 \pm 40$ & $0.20 \pm 0.04$ & $0.20 \pm 0.04$ \\
\hline H347F & $1.6 \pm 0.1$ & $7.4 \pm 1.2$ & $0.21 \pm 0.01$ & $28 \pm 2$ \\
\hline $\mathrm{H} 347 \mathrm{E}$ & $>500$ & $470 \pm 40$ & $0.08 \pm 0.01$ & $0.17 \pm 0.03$ \\
\hline \multicolumn{5}{|c|}{$\mathrm{H} 4$ peptide $\left(\mathrm{A}_{15} \mathrm{~K}_{16} \mathrm{R}_{17} \mathrm{H}_{18} \mathrm{R}_{19} \mathrm{~K}_{20} \mathrm{~V}_{21} \mathrm{~L}_{22} \mathrm{R}_{23} \mathrm{D}_{24}\right)$} \\
\hline R17A & N.B. & N.A. & N.A. & N.A. \\
\hline R17E & N.B. & N.A. & N.A. & N.A. \\
\hline R17Q & $>500$ & $1980 \pm 50$ & $0.12 \pm 0.01$ & $0.06 \pm 0.005$ \\
\hline R17K & $240 \pm 10$ & $1890 \pm 70$ & $0.14 \pm 0.04$ & $0.07 \pm 0.002$ \\
\hline H18A & N.B. & N.A. & N.A. & N.A. \\
\hline $\mathrm{H} 18 \mathrm{~F}$ & $120 \pm 4$ & $420 \pm 7$ & $0.35 \pm 0.03$ & $0.84 \pm 0.07$ \\
\hline $\mathrm{H} 18 \mathrm{E}$ & N.B. & - & - & $0.09 \pm 0.008$ \\
\hline R19A & $41 \pm 1$ & $310 \pm 7$ & $0.34 \pm 0.02$ & $1.1 \pm 0.1$ \\
\hline R19E & $230 \pm 10$ & $1990 \pm 90$ & $0.24 \pm 0.04$ & $0.12 \pm 0.02$ \\
\hline R19Q & $88 \pm 2$ & $530 \pm 9$ & $0.28 \pm 0.01$ & $0.53 \pm 0.02$ \\
\hline R19K & $39 \pm 1$ & $360 \pm 4$ & $0.39 \pm 0.03$ & $1.1 \pm 0.1$ \\
\hline $\mathrm{V} 21 \mathrm{~A}$ & $16 \pm 1$ & $390 \pm 10$ & $0.11 \pm 0.02$ & $0.29 \pm 0.05$ \\
\hline $\mathrm{V} 21 \mathrm{~F}$ & $54 \pm 3$ & $160 \pm 6$ & $0.35 \pm 0.04$ & $2.1 \pm 0.3$ \\
\hline L22A & N.B. & - & - & $0.02 \pm 0.004$ \\
\hline L22F & $31 \pm 2$ & $110 \pm 2$ & $0.36 \pm 0.02$ & $3.2 \pm 0.2$ \\
\hline $\mathrm{R} 23 \mathrm{~A}$ & $27 \pm 1$ & $210 \pm 5$ & $0.36 \pm 0.03$ & $1.7 \pm 0.1$ \\
\hline R23L & $3.8 \pm 0.1$ & $22 \pm 1$ & $0.40 \pm 0.06$ & $22 \pm 3$ \\
\hline R23E & $27 \pm 2$ & $290 \pm 20$ & $0.26 \pm 0.06$ & $0.91 \pm 0.22$ \\
\hline
\end{tabular}

$(>500)$ A lower limit of the $\mathrm{K}_{\mathrm{D}}$ value is reported because saturation of the enzyme with ligand could not be achieved during ITC titrations.

(N.B.) No heat of binding was detected using ITC.

(N.A.) No activity was detected in the methyltransferase assay. (-) The individual values of $K_{M}$ and $k_{c a t}$ are not reported because the $K_{M}$ value is beyond the measurable range; the $k_{c a t} / K_{M}$ values are reported in these cases.

deep cleft formed by the $\beta 6$-strand and iSET $\alpha 2$-helix on one side and the loop connecting the $\beta 12$-strand and the cSET $\alpha 3$-helix on the other (Fig. 1B). To facilitate the discussion of histone $\mathrm{H} 4$ recognition by hSET8, we have divided the analysis of its binding into three categories based on (1) interactions with the $\mathrm{H} 4$ peptide backbone, (2) contacts with the side chains of residues $\mathrm{N}$-terminal to Lys-20 in H4, and (3) side-chain interactions with residues C-terminal to Lys-20. The peptide backbone of histone $\mathrm{H} 4$ is anchored in the substrate-binding cleft through the formation of a parallel $\beta$-sheet with the $\beta 6$ strand (Fig. 3A) and hydrogen-bonds with the side chains of Gln-276, Asp-338, and His-347 (Fig. 3B). Lys-20 is at the center of this $\beta$-sheet interaction, which firmly deposits the lysine side chain into the active site. A comparison of the hSET8:histone H4 complex with the structures of DIM-5 (Zhang et al. 2003) and hSET7/9 (Xiao et al. 2003a) bound to histone $\mathrm{H} 3$ reveals that the parallel $\beta$-sheet-binding mode is conserved among the three PKMTs, although the substrate-binding cleft of hSET8 is deeper and more pronounced than in the other enzymes (Fig. 3A).

To probe the interactions between hSET 8 and the H4 backbone, we mutated Asp-338 and His-347 and measured their effects on histone binding and methylation (Table 2). Substitution of Asp-338 to asparagine and alanine in hSET8 abolishes both histone $\mathrm{H} 4$ binding and methylation. The results of the asparagine mutation are surprising because its amide side chain would be expected to maintain hydrogen bonding with the backbone amide of Arg-19 in H4. However, the carboxylate of Asp338 also hydrogen-bonds to the amide of Ser-340 in the cSET region, indicating that this residue forms a hydrogen-bond bridge between this serine and Arg-19 in H4 that cannot be maintained in the D338N mutant. Mutation of His-347 to alanine, glutamate, or phenylalanine has variable effects on the affinity and methylation of histone H4. The glutamate and alanine substitutions weaken the interactions between $\mathrm{H} 4$ and hSET8 as determined by ITC and also reduce the substrate specificity by approximately fivefold. In contrast, the H347F mutation enhances the affinity of hSET8 for histone $\mathrm{H} 4$ as judged by the decrease in the $\mathrm{K}_{\mathrm{D}}$ and $K_{M}$ values versus the wild-type enzyme, despite the loss of hydrogen bonding between the imidazole $\mathrm{N}_{\varepsilon} 2$ atom and the backbone carbonyl of Lys-16 in H4 (see below).

The side chains of the residues in the N-terminal part of the histone $\mathrm{H} 4$ peptide are recognized through an intimate series of hydrogen-bond, salt-bridge, and van der Waals interactions in the substrate-binding cleft of hSET8 (Fig. 3B). The side chain of Arg-17 in histone H4 engages in a complex array of hydrogen bonding within the binding cleft of the enzyme. The guanidinium group hydrogen-bonds to the carbonyl oxygen of Gly-269 and forms water-mediated hydrogen bonds with the backbone amide of Tyr-271 and the carbonyl oxygens of Tyr262 and His-18 in H4. Moreover, the Arg-17 guanidinium moiety engages in a salt-bridge interaction with the carboxylate of Glu-259 and also participates in van der Waals contacts with the sulfhydryl group of Cys270. The side chain of His-18 in histone H4 is also involved in a variety of interactions within the substratebinding cleft. In addition to hydrogen bonding to the ribose 3'-OH of AdoHcy, the imidazole group forms edgeto-face aromatic ring interactions with the side chains of His-347 and Trp-349 in the cSET region and also participates in van der Waals contacts with the sulfhydryl group of Cys-270. The guanidinium group of Arg-19 in $\mathrm{H} 4$ engages in a salt-bridge interaction with the carboxylate of Glu-259 and also forms a cation- $\pi$ interaction with the phenol side chain of Tyr-274. Collectively, these interactions can be grouped into two categories that appear to be important for recognition of the histone H4 N terminus by hSET8: (1) an edge-to-face aromatic cluster comprised of His-347 and Trp-349 in the enzyme and His-18 in $\mathrm{H} 4$ and (2) a salt-bridge network between Arg-17 and Arg-19 in H4 that is bridged by the carboxylate of Glu-259. 
Couture et al.
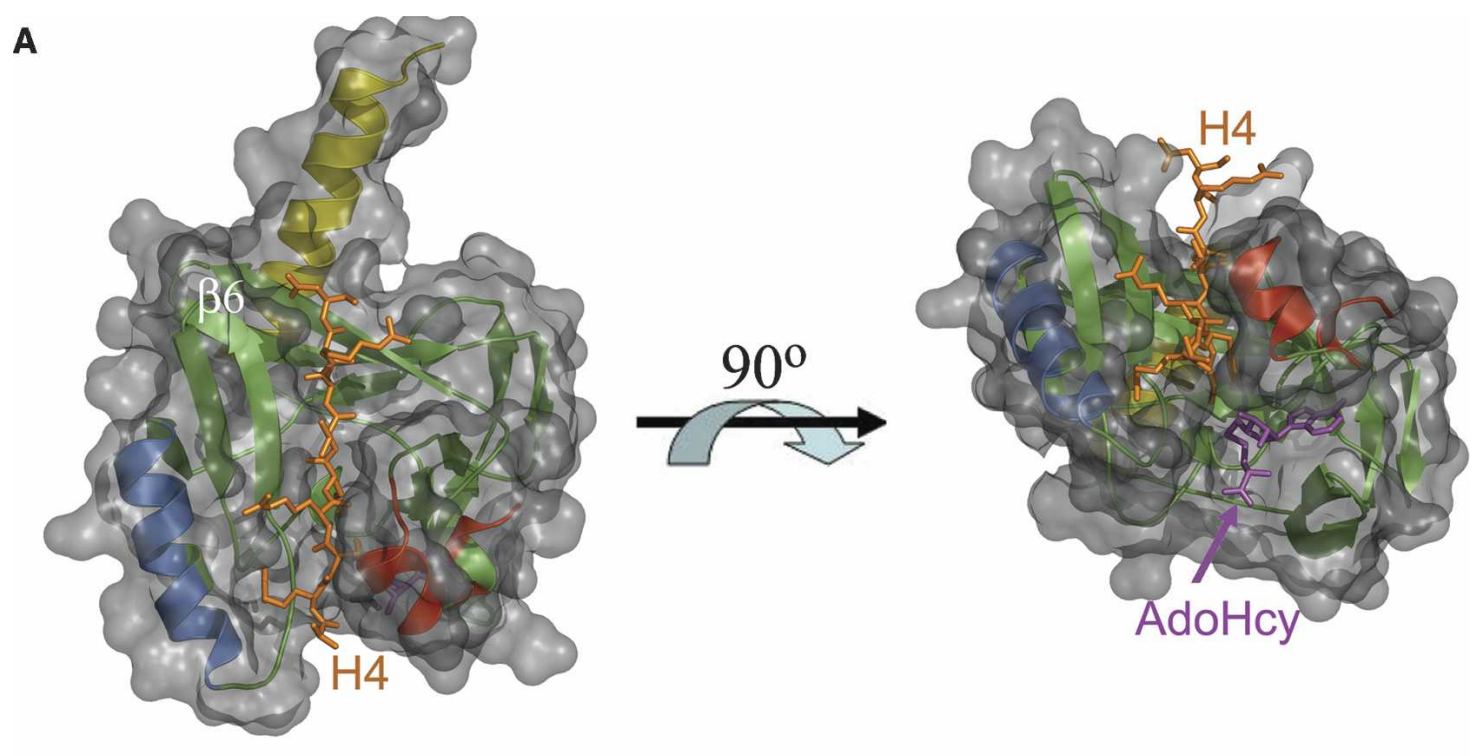

B

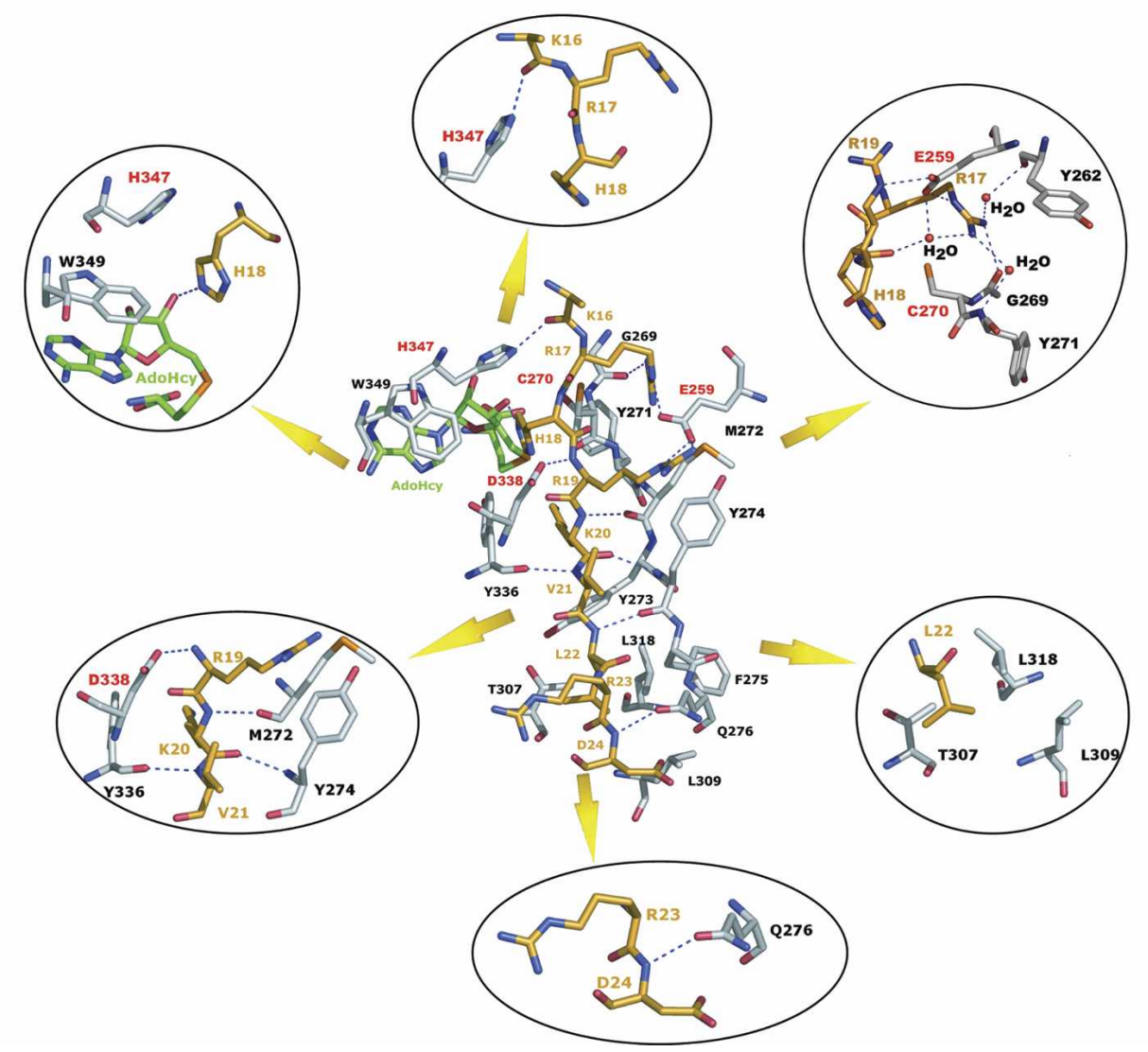

Figure 3. Histone substrate-binding cleft. (A) Two orthogonal views of the molecular surface of the histone-binding cleft of hSET8 in which the $\beta 6$-strand is denoted through the transparent surface. The $\mathrm{H} 4$ peptide and cofactor are rendered in orange and magenta, respectively, while the secondary structure of the enzyme is depicted as in Figure 1B. $(B)$ Substrate-binding cleft of hSET8 in which the carbon atoms of the protein, the $\mathrm{H} 4$ peptide, and the cofactor are illustrated in gray, gold, and green, respectively. Hydrogen bonds are displayed as dashed blue lines. Protein and ligands atoms are labeled according to the color of their carbon atoms, except for mutations in hSET8 that are labeled in red.

To elucidate the determinants of the histone lysine specificity of hSET8, we screened a series of site-directed mutants in the substrate-binding cleft and the $\mathrm{N}$ termi- nus of histone H4. As mentioned above, mutation of the His-347 to phenylalanine in hSET8 markedly increases affinity for histone $\mathrm{H} 4$ by $\sim 30$-fold (Table 2 ). This residue 
participates in the aromatic cluster with Trp-349 and His-18 in H4 (Fig. 3B), and the H347F mutant substantially enhances the edge-to-face interactions among these aromatic residues. In contrast, an alanine mutation of Cys-270, whose sulfhydryl group engages in van der Waals contacts with the imidazole group of His-18 and the guanidinium moiety of Arg-17, severely disrupts histone $\mathrm{H} 4$ binding and methylation. Although this residue does not directly participate in the aromatic cluster or Glu-259 salt bridge, it may serve to orient the side chains of Arg-17 and His-18 within the substrate-binding cleft. In addition to the hSET8 mutations, we mutated His-18 in histone $\mathrm{H} 4$ to determine its effect on the specificity of the enzyme. Interestingly, the substitution of His-18 by phenylalanine does not impact the affinity to nearly the same extent as the H347F substitution in the substratebinding cleft. However, mutation of His-18 to alanine completely abolishes both histone $\mathrm{H} 4$ binding and methylation by hSET8, while a glutamate substitution at this position reduces the $k_{c a t} / K_{M}$ value $\sim 12$-fold (Table 2 ). As discussed previously, His-18 hydrogen-bonds to the ribose moiety of the cofactor, enhancing the binding of AdoMet during histone methylation. Similarly, the indole ring of Trp-349 not only participates in the edge-toface contacts within the aromatic cluster but also engages in a $\pi$-stacking interaction with the adenine ring of the cofactor (Fig. 2A). Collectively, these interactions underscore the fundamental function of the aromatic cluster in both histone $\mathrm{H} 4$ and AdoMet binding.

The salt-bridge network comprised of Glu-259 in hSET8 and Arg-17 and Arg-19 in histone H4 also plays a key role in substrate recognition (Fig. 3B). An alanine mutation of Glu-259, which resides in the iSET $\alpha$-helix of hSET8, eliminates this salt-bridge network and dramatically impairs histone $\mathrm{H} 4$ binding, emphasizing its importance in substrate specificity (Table 2). Conversely, an E259Q substitution modestly reduces histone $\mathrm{H} 4$ binding and methylation by hSET8, indicating that hydrogen bonding between this mutant's amide side chain and the $\mathrm{H} 4$ arginines can partially compensate for the loss of the ionic interactions in the salt-bridge network. To identify if Arg-17 or Arg-19 (or both) is required for histone $\mathrm{H} 4$ recognition by the enzyme, we mutated each of these residues to alanine, glutamate, glutamine, or lysine, respectively. Mutation of Arg-17 to alanine or glutamate completely abolishes histone $\mathrm{H} 4$ binding and methylation, while the lysine and glutamine substitutions retain residual activity as substrates. The results with the R17K H4 mutant were somewhat surprising because of the conservation of the positive charge, which can maintain a salt bridge with the carboxylate of Glu259. Collectively, the Arg-17 mutations strongly suggest that its guanidinium group is specifically recognized through the salt-bridge interaction with Glu-259 and by direct and water-mediated hydrogen bonds within the substrate-binding cleft of hSET8. Whereas the Arg-17 mutants abrogate interactions between the enzyme and histone H4, substitutions of Arg-19 have little impact on either $\mathrm{H} 4$ binding or methylation, with the exception of the R19E mutant, which reduces affinity for the enzyme due to its negatively charged carboxylate group. To summarize, our results reveal that the salt bridge formed between Glu-259 in hSET8 and Arg-17 in histone H4 is a prerequisite for substrate binding and methylation of Lys-20 by hSET8.

In contrast to the $\mathrm{N}$-terminal part of histone $\mathrm{H} 4$, most of the residues C-terminal to Lys-20 are solvent-exposed and do not engage in significant interactions with hSET8 (Fig. 3B). For example, mutations of Val-21 in H4 to alanine or phenylalanine have only modest effects on substrate binding and methylation by the enzyme (Table 2). However, substitution of the neighboring Leu-22 by alanine virtually abolishes histone $\mathrm{H} 4$ binding and reduces the substrate specificity of the enzyme $>50$-fold. An inspection of the substrate-binding cleft reveals that this leucine binds in a shallow hydrophobic pocket formed by the aliphatic side chains of Thr-307, Leu-309, and Leu318 in hSET8. Mutation of Leu-22 to a phenylalanine is readily accommodated in this position, indicating that this hydrophobic pocket is a key determinant in histone $\mathrm{H} 4$ recognition. The side chains of the remaining residues in the $\mathrm{H} 4$ peptide, Arg-23 and Asp-24, do not engage in extensive interactions within the substrate-binding cleft of the enzyme. To illustrate this, substitution of Arg-23 by alanine or glutamate has no significant effect on $\mathrm{H} 4$ binding and methylation. Intriguingly, an R23L mutation results in an $\sim 10$-fold increase in the affinity of hSET8 for histone $\mathrm{H} 4$, as judged by its $\mathrm{K}_{\mathrm{D}}$ and $K_{M}$ values. It is difficult to reconcile this observation with the solvent exposure of Arg-23 in the structure of the ternary complex. However, we hypothesize that the peptide backbone of the H4 R23L mutant may adopt a different conformation when bound to hSET8, permitting this residue to engage in hydrophobic interactions with the enzyme similar to those observed for Leu-22. Taken together, these results reveal that the $\mathrm{C}$ terminus of histone $\mathrm{H} 4$ is anchored in the substrate-binding cleft of hSET8 through a hydrophobic specificity pocket that recognizes Leu-22 or other bulky hydrophobic residues in this position.

Based on our collective biochemical and structural analyses of the histone H4 specificity of hSET8, we identify a consensus motif for substrate recognition by this PKMT: R- $\Omega-\zeta-\underline{K}-\mathrm{X}-\Phi$ (where $\Omega$ is an aromatic residue, $\zeta$ is a nonacidic residue, $\underline{\mathbf{K}}$ is the methylation site, $\mathrm{X}$ is any residue, and $\Phi$ is a bulky hydrophobic residue) (Aasland et al. 2002). The arginine (R) and an aromatic residue $(\Omega)$ are required in the $\mathrm{N}$ terminus of this motif because they engage in highly specific interactions within the saltbridge network and aromatic cluster, respectively. The methylation site $\underline{\mathbf{K}}$ is preceded by any nonacidic residue

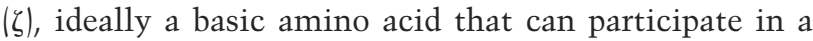
salt-bridge interaction with Glu-259 in the substratebinding cleft. At the $\mathrm{C}$ terminus of the motif, a bulky hydrophobic residue $(\Phi)$ is recognized through its binding in the hydrophobic specificity pocket of the substrate-binding cleft.

A comparison of the hSET8:histone $\mathrm{H} 4$ complex with the histone H3-bound structures hSET7/9 and DIM-5 (which methylate Lys-4 and Lys-9 in H3, respectively) 
reveals substantial differences in substrate recognition by these PKMTs. In the crystal structure of DIM- 5 bound to histone $\mathrm{H} 3$ (Zhang et al. 2003), the enzyme forms an extended parallel $\beta$-sheet with the peptide backbone of $\mathrm{H} 3$, similar to the hSET8:histone H4 complex. However, the side chains of histone $\mathrm{H} 3$ participate in few contacts within the substrate-binding cleft of DIM-5, unlike the intimate series of interactions that are critical for histone $\mathrm{H} 4$ recognition by hSET8. Recent studies of the substrate specificity of hSET7/9 have revealed that it recognizes a consensus motif in its protein substrates: K/R$\mathrm{S} / \mathrm{T}-\underline{K}$ (in which $\underline{\mathbf{K}}$ is the methylation site) (Chuikov et al. 2004). Although hSET7/9 recognizes a specific series of residues preceding its methylation site, this PKMT does not form an extensive $\beta$-sheet with the protein substrate, unlike DIM-5 and hSET8. To summarize, the histone specificity of hSET8 appears to be a combination of the substrate-binding modes of DIM-5 and hSET7/9 in which the enzyme not only engages in an extended parallel $\beta$-sheet with $\mathrm{H} 4$, but also recognizes the residues flanking Lys-20 through an extensive network of sidechain interactions (Fig. 3B).

\section{Product specificity of hSET8}

Analyses of histone H4 Lys-20 methylation patterns in Drosophila and HeLa cells suggest that hSET8 functions as a monomethylase. However, the degree of methylation of Lys-20 catalyzed by this enzyme, commonly referred to as the product specificity of a PKMT (Zhang et al. 2003), has not been rigorously established. To determine the product specificity of hSET8, we conducted histone methyltransferase assays and subjected aliquots of the reaction to MALDI mass spectrometry to determine the methylation state of Lys-20 in histone H4. The data indicate a shift in the mass/charge $(\mathrm{m} / \mathrm{z})$ ratio from 1320 to 1334 in the $\mathrm{H} 4$ peptide after its reaction with hSET8, corresponding to the addition of a single methyl group (Fig. 4A). Incubation of the enzyme with the $\mathrm{H} 4$ peptide for $24 \mathrm{~h}$ results in a complete conversion to monomethyl-Lys-20 with no discernible accumulation of the di- or trimethylated states (data not shown). Thus, wild-type hSET8 is a bona fide histone H4 Lys-20 monomethylase, correlating with its in vivo function in maintaining Lys-20 monomethylation during cell division.

After characterizing the product specificity of hSET8, we sought to understand the mechanisms that control lysine monomethylation by this PKMT. Examination of the active site reveals two residues, Tyr-245 and Tyr334 , that hydrogen-bond to the $\varepsilon$-amino group of Lys-20 through direct and water-mediated interactions, respectively (Fig. 4B). The positions of the hydroxyl groups of these tyrosines are structurally conserved with Tyr-245 and Tyr-305, respectively, in the active site of hSET7/9 (Fig. 4C). The Tyr-245/Tyr-305 pair hydrogen-bonds to the $\varepsilon$-amino group of Lys- 4 in histone $\mathrm{H} 3$ and arrests catalysis at the monomethylation state through stabilization of the methyllysine product complex in hSET7/9 (Fig. 4C; Xiao et al. 2003a; Zhang et al. 2003). The structural similarities of the lysine-binding channels of these

A
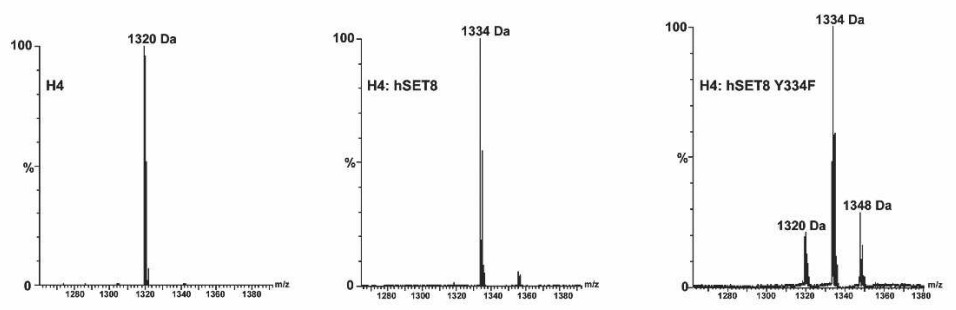

B
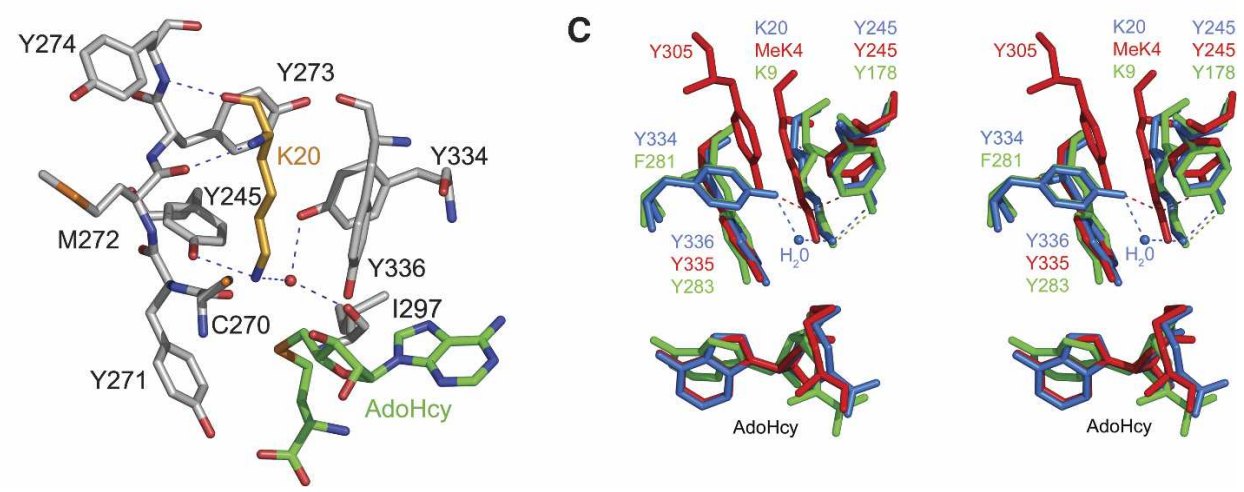

Figure 4. Product specificity of hSET8. (A) MALDI mass spectrometry of the 10-residue histone H4 peptide $(\mathrm{m} / \mathrm{z}=1320)$ and its methylation by wild-type hSET8 and the Y334F mutant. (B) Close-up view of hSET8 lysine-binding channel. Residues and the water molecule that interact with the side chain of Lys-20 are illustrated. Hydrogen bonds are rendered as dashed blue lines. The carbon atoms of Lys-20, AdoHcy, and the enzyme are depicted in gold, green, and gray, respectively. (C) Stereoview of a superimposition of the lysine-binding channels of hSET8:H4 Lys-20 (blue), hSET7/9:H3 MeLys4 (1O9S.pdb, red), and DIM-5:H3 Lys-9 (1PEG.pdb, green). Hydrogen bonds are rendered with dashed lines corresponding to the color of each enzyme. 
Table 3. Mutational analysis of the tyrosines within the lysine binding channel of hSET8

\begin{tabular}{lcccr}
\hline Lysine pore & $\mathrm{K}_{\mathrm{D}}(\mu \mathrm{M})$ & $K_{m}(\mu \mathrm{M})$ & $k_{\text {cat }}\left(\mathrm{min}^{-1}\right)$ & $k_{\text {cat }} / K_{m}\left(\mu \mathrm{M}^{-1} \times \mathrm{min}^{-1}\right) \times 10^{3}$ \\
\hline Wild type & $33 \pm 1$ & $400 \pm 30$ & $0.43 \pm 0.02$ & $1.1 \pm 0.1$ \\
Y245A & $>500$ & N.A. & N.A. & N.A. \\
Y245F & $>500$ & N.A. & N.A. & N.A. \\
Y334A & $>500$ & $520 \pm 30$ & - & $0.45 \pm 0.11$ \\
Y334F & $19 \pm 2$ & $0.005 \pm 0.001$ \\
\hline
\end{tabular}

$(>500)$ A lower limit of the $\mathrm{K}_{\mathrm{D}}$ value is reported because saturation of the enzyme with ligand could not be achieved during ITC titrations.

(N.A.) No activity was detected in the methyltransferase assay.

$(-)$ The individual values of $K_{M}$ and $k_{c a t}$ are not reported because the $K_{M}$ value is beyond the measurable range; the $k_{c a t} / K_{M}$ values are reported in these cases.

two PKMTs provide a mechanistic explanation for the product specificity of hSET8. To further probe the methyltransfer properties of the enzyme, we superimposed its active site with DIM-5, a histone H3 Lys-9-specific methyltransferase (Fig. 4C). The alignment reveals that Tyr-245 in hSET8 is structurally conserved with Tyr-178 in DIM-5, whereas Tyr-334 aligns with a phenylalanine (Phe-281), respectively. The absence of a second hydrogen-bonding tyrosine in the active site of DIM-5 enables this PKMT to catalyze trimethylation of Lys-9 in H3 (Zhang et al. 2003). Based on this observation, we hypothesized that mutation of either Tyr-245 or Tyr-334 in the active site of hSET8 might convert the product specificity of this PKMT to either a Lys-20 di- or trimethylase.

To test this hypothesis, we mutated each of these tyrosines to alanine or phenylalanine, respectively, and determined the enzymatic activity and product specificity of each mutant. Mutation of Tyr-334 to phenylalanine has virtually no effect on histone $\mathrm{H} 4$ binding or methylation by hSET8, whereas an alanine substitution at this position severely compromises enzymatic activity (Table 3). Mass spectrometric analysis of the Y334F mutant reveals that it is capable of catalyzing mono- and dimethylation of Lys-20 in histone H4 (Fig. 4A). Reaction of the $\mathrm{H} 4$ peptide with the Y334F mutant for $24 \mathrm{~h}$ primarily yields dimethyl-Lys-20 with no detectible trimethylation of this residue (data not shown). These results are consistent with our prediction based on the active-site alignment with DIM-5 and also agree with the structurally homologous Y305F mutation in hSET7/ 9, which converts this PKMT to a histone H3 Lys-4 dimethylase (Fig. 4C; Zhang et al. 2003). In contrast, mutation of Tyr-245 to either alanine or phenylalanine completely abolishes methyltransfer by hSET8. The effects of these substitutions correlate with mutations of the structurally conserved Tyr-245 in hSET7/9 that disrupt the activity of this PKMT (Xiao et al. 2003a). Taken together, the mutational analysis of Tyr-245 and Tyr-334 in the active site of hSET8 provides a molecular basis for histone H4 Lys-20 monomethylation by this PKMT. Moreover, our results concur with the Phe/Tyr switch model recently proposed by Cheng and colleagues in which the presence or absence of specific tyrosines within the lysine-binding channel governs the product specificity of SET-domain PKMTs (Collins et al. 2005).

\section{Conclusions}

In summary, the biochemical and structural studies of hSET8 presented herein have elucidated the mechanisms by which this PKMT recognizes histone H4 Lys20, permitting the identification of a consensus methylation motif for the enzyme. It will be interesting to determine whether other H4 Lys-20-specific methyltransferases, such as SUV4-20H1/2 (Schotta et al. 2004), exhibit a similar specificity for the residues that flank this lysine. In addition, our analysis of the product specificity of hSET8 has established that this enzyme is a Lys-20 monomethylase, in agreement with previous reports of histone $\mathrm{H} 4$ methylation in HeLa cells (Julien and Herr 2004) and Drosophila (Karachentsev et al. 2005). Despite the role of this PKMT in maintaining Lys-20 monomethylation during the cell cycle, the mechanisms by which this modification mediates transcriptional silencing are currently unresolved. Identifying effector proteins that specifically recognize the monomethylated state of Lys-20 will be pivotal in gaining a complete perspective of the regulatory functions of SET8 in mitosis and gene expression in metazoans.

\section{Materials and methods}

\section{Cloning and expression of hSET8}

A construct of hSET8 encoding residues 191-352 was cloned into the parallel expression vector pHIS2 using BamHI and XhoI restriction sites (Sheffield et al. 1999). The enzyme was then overexpressed in Escherichia coli BL21 (DE3) Codon Plus RIL cells (Stratagene) at $17^{\circ} \mathrm{C}$ and purified to homogeneity using Talon $\mathrm{Co}^{2+}$ (Clontech) affinity and Superdex 75 (Amersham Biosciences) gel filtration chromatographies, essentially as reported for pea Rubisco LSMT (Trievel et al. 2002) (with the exception that gel filtration was performed in $20 \mathrm{mM}$ Tris- $\mathrm{HCl}$ at $\mathrm{pH}$ 7.0, $100 \mathrm{mM} \mathrm{NaCl}$, and $10 \mathrm{mM} \beta$-mercaptoethanol). Mutants of hSET8 were prepared using the QuikChange Site-Directed Mutagenesis Kit (Stratagene), and the sequences were verified by dideoxy sequencing. Mutants of hSET8 were expressed and purified as described for the wild-type enzyme.

\section{Histone $H 4$ peptides}

Wild-type and mutant histone $\mathrm{H} 4$ peptides (sequence: $\mathrm{A}_{15^{-}} \mathrm{K}_{16^{-}}$ $\mathrm{R}_{17}-\mathrm{H}_{18}-\mathrm{R}_{19}-\mathrm{K}_{20}-\mathrm{V}_{21}-\mathrm{L}_{22}-\mathrm{R}_{23}-\mathrm{D}_{24}$ ) were purchased from New England Peptide, Inc. Peptides were synthesized with $\mathrm{N}$-terminal 
acetyl and C-terminal amide groups and were delivered as 2.5mg lyophilized aliquots that were resuspended in deionized water to the appropriate concentration prior to use.

\section{Crystallization and structure determination}

Selenomethionyl-derivatized hSET8 containing an I220M mutation was prepared according to the protocol of Doublie (1997). Native and SeMet crystals of the ternary complex were obtained in 25\%-35\% Pentaerythritol Ethoxylate $(15 / 4), 50 \mathrm{mM}$ $\left(\mathrm{NH}_{4}\right)_{2} \mathrm{SO}_{4}$, and $100 \mathrm{mM}$ Bis-TRIS (pH 6.0-7.0) at $4^{\circ} \mathrm{C}$ using 40 $\mathrm{mg} / \mathrm{mL}$ hSET8 and a twofold molar ratio of the histone $\mathrm{H} 4$ peptide and AdoHcy. Crystals were then harvested in mother liquor and directly flash-frozen in liquid nitrogen. A selenomethionyl multiwavelength anomalous dispersion (MAD) experiment was conducted at the 32-ID beamline of COM-CAT at the Advanced Photon Source Synchrotron. Data were collected on a single crystal of the I220M mutant at the selenium edge with a Mar165 CCD detector (Mar Research) and subsequently processed and scaled using Denzo and Scalepack (Table 1; Otwinowski and Minor 1997). A complete high-resolution data set was also collected to $1.45 \AA$ using a single crystal of native hSET8. After processing and scaling the peak, inflection point, and high remote wavelength data sets, the data were submitted for structure determination in the Automated Crystallographic System (ACrS) (Brunzelle et al. 2003). The best solution resulted from the HySS (Grosse-Kunstleve and Adams 2003), SHARP (de la Fortelle and Bricogne 1997), DM/Solomon (Cowtan and Main 1993; Abrahams and Leslie 1996), and ARP/wARP (Perrakis et al. 1999) pathway. The $2.0 \AA$ experimental map was readily interpretable and permitted automated model building in ARP/ wARP (Fig. 1A). The resulting hSET8 model was then used for molecular replacement with the native data set in MOLREP (Vagin and Teplyakov 1997). Four molecules were located in the triclinic cell, which were then used for model building in $\mathrm{O}$ (Jones et al. 1991) and refinement in REFMAC (Murshudov et al. 1997). In later stages of refinement, water molecules were added, and residues with alternative conformations were modeled. In the final model, Ala-15 and the side chain of Lys-16 were omitted due to poor electron density in the $\mathrm{N}$ terminus of the $\mathrm{H} 4$ peptide. The final structure has $\mathrm{R}_{\text {working }}$ and $\mathrm{R}_{\text {free }}$ values of $16.9 \%$ and $19.9 \%$, respectively (Table 1 ) and excellent geometry with none of the nonglycine residues present in the disallowed regions of the Ramachandran plot. Structural figures were generated and rendered in PyMOL (http://www.pymol.org).

\section{Isothermal titration calorimetry}

The equilibrium dissociation constants of wild type and mutants of hSET8 and histone H4 were determined using a VP-ITC calorimeter (MicroCal, LLC). The enthalpies of binding of wild type and mutants of hSET8 $(60-120 \mu \mathrm{M})$ and the histone $\mathrm{H} 4$ peptide $(1.0-2.0 \mathrm{mM})$ were measured at $20^{\circ} \mathrm{C}$ in $20 \mathrm{mM}$ sodium phosphate ( $\mathrm{pH} 7.0)$ and $100 \mathrm{mM} \mathrm{NaCl}$. A saturating concentration of AdoHcy (1.0-2.0 mM) was used in all titrations. ITC data were subsequently analyzed using Origin 7.0 (OriginLab Corp.) with blank injections of ligand into buffer subtracted from the experimental titrations prior to data analysis. All of the calculated binding curves had $N$-values between 0.85 and 1.00 . Curve-fitting errors for each experiment are reported in Tables 2 and 3 .

\section{Histone methyltransferase assays}

The steady-state kinetic parameters for wild type and mutants of hSET8 and histone H4 were determined using a coupled fluorescent methyltransferase assay recently developed in our laboratory (Collazo et al. 2005). S-adenosylmethionine (AdoMet) was purified by cation exchange to remove impurities present in the commercially available cofactor, as described by Barker and coworkers (Chirpich et al. 1970). Assays were performed in 100 mM HEPES buffer $(\mathrm{pH} 7.5)$ and $0.02 \%$ maleimide-treated BSA with $0.5-2.0 \mu \mathrm{M}$ hSET8, a saturating concentration of AdoMet $(50$ $\mu \mathrm{M})$, and varying concentrations of histone $\mathrm{H} 4$ peptide. Assays were performed in duplicate with a final volume of $150 \mu \mathrm{L}$. To determine the $K_{M}$ and $k_{c a t}$ values, peptide concentrations were varied from 0.05 to $4.0 \mathrm{mM}$. In cases in which the $K_{M}$ value was too high to be accurately measured $(>2.5 \mathrm{mM})$, the substrate specificity $\left(k_{c a t} / K_{M}\right)$ was determined by varying the $\mathrm{H} 4$ peptide concentration (0.16-0.64 mM) below the $K_{M}$ value. This simplification permits the $k_{c a t} / K_{M}$ value to be determined from the linear relationship between the initial velocity and substrate concentration within this range of the Michaelis-Menten plot. Fluorescence was measured using a GeniosPro microplate reader (Tecan), and initial velocities were calculated by a linear fit from the plot of the fluorescence values versus time. The steady-state kinetics parameters were then calculated by plotting the velocity versus peptide concentration and fitting the Michaelis-Menten equation to the data in SigmaPlot (Systat Software, Inc.).

\section{Mass spectrometry analysis}

Histone methyltransferase assays were performed with wildtype hSET8 and the Tyr-245 and Tyr-334 mutants $(5 \mu \mathrm{M})$ as described above and were quenched after $15 \mathrm{~min}$ or $24 \mathrm{~h}$ by the addition of $0.5 \%$ trifluoroacetic acid. Aliquots of the samples were cocrystallized with $\alpha$-cyano-4-hydroxycinnamic acid (1:1), applied on the target, and dried at room temperature. The mass spectra were acquired on the TofSpec 2E MALDI-TOF mass spectrometer (Waters, Inc.) in reflectron mode, with each spectrum representing the average of 50 laser shots. Close external calibration was used based on the following mixture: bradikinin fragment $1-8, \mathrm{~m} / \mathrm{z}=904.41$ (for $[\mathrm{M}+\mathrm{H}]+$ ); angiotensin II, $\mathrm{m} / \mathrm{z}=1046.54$; [Glu1]-fibrinopeptide $\mathrm{B}, \mathrm{m} / \mathrm{z}=1570.68$; ACTH (clip 18-39), $\mathrm{m} / \mathrm{z}=2465.20$.

\section{Acknowledgments}

We thank Yi Zhang for providing us the clone of human SET8, John Quintana and Zdzislaw Wawrzak for their assistance in X-ray data collection, Robert Houtz for his gift of purified AdoMet, and Henriette Remmer for her assistance with MALDI mass spectrometry. We also acknowledge Daniel Bochar, Roland Kwok, Patrick O'Brien, and Daniel Peisach for reading the manuscript and providing useful comments. Use of the Advanced Photon Source was supported by the U.S. Department of Energy, Office of Science, Office of Basic Sciences, under contract number W-31-109-Eng-38. The authors gratefully acknowledge the Michigan Economic Development Corporation and the Michigan Technology Tri-Corridor for the support of this research program (grant 085P1000817). The coordinates for the hSET8:histone H4:AdoHcy complex have been deposited in the Research Collaboratory for Structural Bioinformatics under accession code 1ZKK.pdb

\section{References}

Aasland, R., Abrams, C., Ampe, C., Ball, L.J., Bedford, M.T., Cesareni, G., Gimona, M., Hurley, J.H., Jarchau, T., Lehto, V.P., et al. 2002. Normalization of nomenclature for peptide motifs as ligands of modular protein domains. FEBS Lett. 513: $141-144$.

Abrahams, J.P. and Leslie, A.G.W. 1996. Methods used in the 
structure determination of bovine mitochondrial F1 ATPase. Acta Crystallogr. D Biol. Crystallogr. 52: 30-42.

Beisel, C., Imhof, A., Greene, J., Kremmer, E., and Sauer, F. 2002. Histone methylation by the Drosophila epigenetic transcriptional regulator Ash1. Nature 419: 857-862.

Brunzelle, J.S., Shafaee, P., Yang, X., Weigand, S., Ren, Z., and Anderson, W.F. 2003. Automated crystallographic system for high-throughput protein structure determination. Acta Crystallogr. D Biol. Crystallogr. 59: 1138-1144.

Chirpich, T.P., Zappia, V., Costilow, R.N., and Barker, H.A. 1970. Lysine 2,3-aminomutase. Purification and properties of a pyridoxal phosphate and S-adenosylmethionine-activated enzyme. J. Biol. Chem. 245: 1778-1789.

Chuikov, S., Kurash, J.K., Wilson, J.R., Xiao, B., Justin, N., Ivanov, G.S., McKinney, K., Tempst, P., Prives, C., Gamblin, S.J., et al. 2004. Regulation of p53 activity through lysine methylation. Nature 432: 353-360.

Collazo, E., Couture, J.-F., Bulfer, S., and Trievel, R.C. 2005. A coupled fluorescent assay for histone methyltransferases. Anal. Biochem. (in press).

Collins, R.E., Tachibana, M., Tamaru, H., Smith, K.M., Jia, D., Zhang, X., Selker, E.U., Shinkai, Y., and Cheng, X. 2005. In vitro and in vivo analyses of a Phe/Tyr switch controlling product specificity of histone lysine methyltransferases. $J$. Biol. Chem. 280: 5563-5570.

Cowtan, K. and Main, P. 1993. Improvement of macromolecular electron density maps by the simultaneous application of real and reciprocal space constraints. Acta Crystallogr. D Biol. Crystallogr. 49: 148-157.

de la Fortelle, E. and Bricogne, G. 1997. Maximum-likelihood heavy-atom parameter refinement for multiple isomorphous replacement and multiwavelength anomalous diffraction methods. Methods Enzymol. 276: 474-492.

Doublie, S. 1997. Preparation of selenomethionyl proteins for phase determination. In Methods in Enzymology (eds. C.W. Carter and R.M. Sweet), pp. 523-530. Academic Press, New York.

Fang, J., Feng, Q., Ketel, C.S., Wang, H., Cao, R., Xia, L., Erdjument-Bromage, H., Tempst, P., Simon, J.A., and Zhang, Y. 2002. Purification and functional characterization of SET8, a nucleosomal histone H4-lysine 20-specific methyltransferase. Curr. Biol. 12: 1086-1099.

Fischle, W., Wang, Y., and Allis, C.D. 2003. Histone and chromatin cross-talk. Curr. Opin. Cell Biol. 15: 172-183.

Georgi, A.B., Stukenberg, P.T., and Kirschner, M.W. 2002. Timing of events in mitosis. Curr. Biol. 12: 105-114.

Grosse-Kunstleve, R.W. and Adams, P.D. 2003. Substructure search procedures for macromolecular structures. Acta Crystallogr. D Biol. Crystallogr. 59: 1966-1973.

Jones, T.A., Zou, J.Y., Cowan, S.W., and Kjeldgaard, M. 1991. Improved methods for building protein models in electron density maps and the location of errors in these models. Acta Crystallogr. A 47: 110-119.

Julien, E. and Herr, W. 2004. A switch in mitotic histone H4 lysine 20 methylation status is linked to $M$ phase defects upon loss of HCF-1. Mol. Cell 14: 713-725.

Karachentsev, D., Sarma, K., Reinberg, D., and Steward, R. 2005. PR-Set7-dependent methylation of histone H4 Lys 20 functions in repression of gene expression and is essential for mitosis. Genes \& Dev. 19: 431-435.

Kuzmichev, A., Jenuwein, T., Tempst, P., and Reinberg, D. 2004. Different ezh2-containing complexes target methylation of histone $\mathrm{H} 1$ or nucleosomal histone H3. Mol. Cell 14: 183-193.

Murshudov, G.N., Vagin, A.A., and Dodson, E.J. 1997. Refinement of macromolecular structures by the maximum-likelihood method. Acta Cryst. D 53: 240-255.
Nishioka, K., Rice, J.C., Sarma, K., Erdjument-Bromage, H., Werner, J., Wang, Y., Chuikov, S., Valenzuela, P., Tempst, P., Steward, R., et al. 2002. PR-Set7 is a nucleosome-specific methyltransferase that modifies lysine 20 of histone $\mathrm{H} 4$ and is associated with silent chromatin. Mol. Cell 9: 1201-1213.

Otwinowski, Z. and Minor, W. 1997. Processing of X-ray diffraction data collected in oscillation mode. Methods Enzymol. 276: 307-326.

Perrakis, A., Morris, R., and Lamzin, V.S. 1999. Automated protein model building combined with iterative structure refinement. Nat. Struct. Biol. 6: 458-463.

Rayasam, G.V., Wendling, O., Angrand, P.O., Mark, M., Niederreither, K., Song, L., Lerouge, T., Hager, G.L., Chambon, P., and Losson, R. 2003. NSD1 is essential for early post-implantation development and has a catalytically active SET domain. EMBO J. 22: 3153-3163.

Rice, J.C., Nishioka, K., Sarma, K., Steward, R., Reinberg, D., and Allis, C.D. 2002. Mitotic-specific methylation of histone H4 Lys 20 follows increased PR-Set7 expression and its localization to mitotic chromosomes. Genes \& Dev. 16: 22252230.

Sanders, S.L., Portoso, M., Mata, J., Bahler, J., Allshire, R.C., and Kouzarides, T. 2004. Methylation of histone H4 lysine 20 controls recruitment of Crb2 to sites of DNA damage. Cell 119: 603-614.

Sarg, B., Koutzamani, E., Helliger, W., Rundquist, I., and Lindner, H.H. 2002. Postsynthetic trimethylation of histone $\mathrm{H} 4$ at lysine 20 in mammalian tissues is associated with aging. J. Biol. Chem. 277: 39195-39201.

Schotta, G., Lachner, M., Sarma, K., Ebert, A., Sengupta, R., Reuter, G., Reinberg, D., and Jenuwein, T. 2004. A silencing pathway to induce $\mathrm{H} 3-\mathrm{K} 9$ and $\mathrm{H} 4-\mathrm{K} 20$ trimethylation at constitutive heterochromatin. Genes \& Dev. 18: 1251-1262.

Sheffield, P., Garrard, S., and Derewenda, Z. 1999. Overcoming expression and purification problems of RhoGDI using a family of 'parallel' expression vectors. Protein Expr. Purif. 15: 34-39.

Sims III, R.J., Nishioka, K., and Reinberg, D. 2003. Histone lysine methylation: A signature for chromatin function. Trends Genet. 19: 629-639.

Trievel, R.C. 2004. Structure and function of histone methyltransferases. Crit. Rev. Eukaryot. Gene Expr. 14: 147-170.

Trievel, R.C., Beach, B.M., Dirk, L.M., Houtz, R.L., and Hurley, J.H. 2002. Structure and catalytic mechanism of a SET domain protein methyltransferase. Cell 111: 91-103.

Vagin, A. and Teplyakov, A. 1997. MOLREP: An automated program for molecular replacement. J. Appl. Cryst. 30: 10221025.

Wilson, J.R., Jing, C., Walker, P.A., Martin, S.R., Howell, S.A., Blackburn, G.M., Gamblin, S.J., and Xiao, B. 2002. Crystal structure and functional analysis of the histone methyltransferase SET7/9. Cell 111: 105-115.

Xiao, B., Jing, C., Wilson, J.R., Walker, P.A., Vasisht, N., Kelly, G., Howell, S., Taylor, I.A., Blackburn, G.M., and Gamblin, S.J. 2003a. Structure and catalytic mechanism of the human histone methyltransferase SET7/9. Nature 421: 652-656.

Xiao, B., Wilson, J.R., and Gamblin, S.J. 2003b. SET domains and histone methylation. Curr. Opin. Struct. Biol. 13: 699-705.

Zhang, X., Tamaru, H., Khan, S.I., Horton, J.R., Keefe, L.J., Selker, E.U., and Cheng, X. 2002. Structure of the Neurospora SET domain protein DIM-5, a histone H3 lysine methyltransferase. Cell 111: 117-127.

Zhang, X., Yang, Z., Khan, S.I., Horton, J.R., Tamaru, H., Selker, E.U., and Cheng, X. 2003. Structural basis for the product specificity of histone lysine methyltransferases. Mol. Cell 12: $177-185$. 


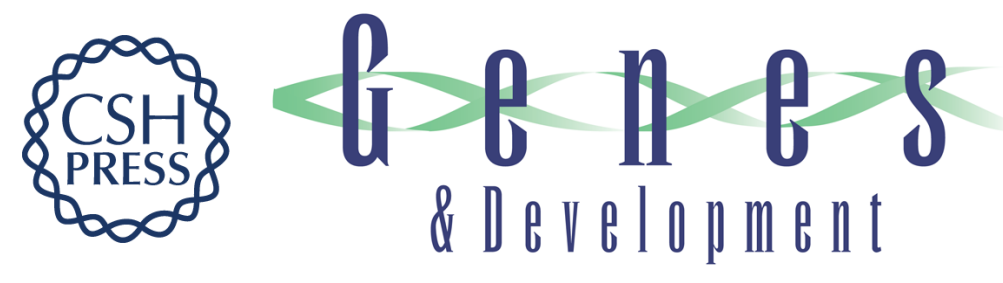

\section{Structural and functional analysis of SET8, a histone H4 Lys-20 methyltransferase}

Jean-François Couture, Evys Collazo, Joseph S. Brunzelle, et al.

Genes Dev. 2005, 19:

Access the most recent version at doi:10.1101/gad.1318405

References

This article cites 35 articles, 7 of which can be accessed free at:

http://genesdev.cshlp.org/content/19/12/1455.full.html\#ref-list-1

\section{License}

Email Alerting

Receive free email alerts when new articles cite this article - sign up in the box at the top Service right corner of the article or click here.

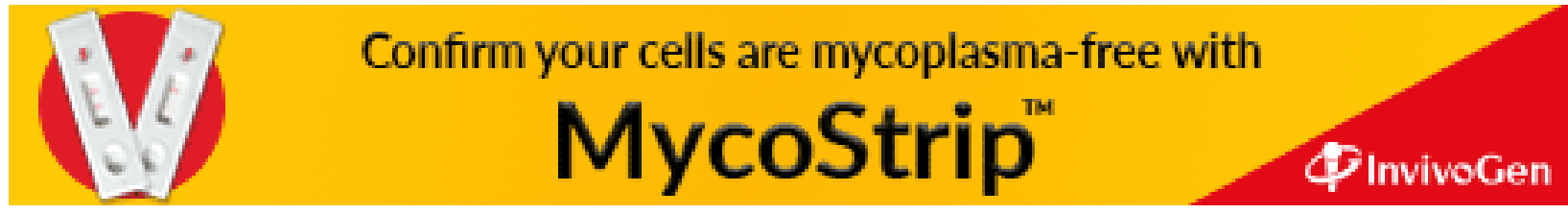

